\title{
Electrolyte Disturbances in Patients with Hyponatremia
}

\author{
George Liamis, Zoi Mitrogianni, Evangelos N. Liberopoulos, \\ Vasilios Tsimihodimos and Moses Elisaf
}

\begin{abstract}
Object Electrolyte abnormalities are frequently observed in patients with hyponatremia. The aim of this study was to determine the incidence of various electrolyte abnormalities encountered in hyponatremic patients admitted to an internal medicine clinic, as well as to investigate the possible pathogenetic mechanisms responsible for these abnormalities.

Patients and Methods We prospectively studied 204 adult patients who either on admission to our clinic or during their hospitalization were found to have hyponatremia.

Results Ninety-two patients (45.5\%) had at least one additional electrolyte abnormality. Hypophosphatemia was the most frequent electrolyte disorder observed (35 patients, 17\%). Hypokalemia was seen in 32 patients $(15.8 \%)$, hypomagnesemia in 31 patients $(15.2 \%)$ and hyperkalemia in 12 patients $(5.9 \%)$. Moreover, 5 patients $(2.5 \%)$ had hyperphosphatemia, 4 patients $(1.9 \%)$ exhibited hypermagnesemia, 3 patients $(1.4 \%)$ had hypercalcemia, and 6 patients $(2.9 \%)$ had true hypocalcemia. There were no statistically significant differences regarding the incidence of these electrolyte abnormalities (as a whole) between the main subgroups of hyponatremic patients (diuretic-induced, syndrome of inappropriate antidiuretic hormone, hypovolemiainduced and edematous state-related). However, hypokalemia and hypomagnesemia were more frequently observed in patients with diuretic-induced hyponatremia, while hyperkalemia was more frequently seen in edematous state-related hyponatremia.
\end{abstract}

Conclusions Additional electrolyte abnormalities are frequently encountered in patients with hyponatremia of any origin admitted to an internal medicine clinic.

Key words: hypokalemia, hypomagnesemia, hypophosphatemia, sodium, diuretics, SIADH

(DOI: 10.2169/internalmedicine.46.6223)

\section{Introduction}

Electrolyte abnormalities are commonly seen in patients with a low serum sodium concentration, and their presence can be helpful in establishing the correct diagnosis regarding the underlying cause of hyponatremia $(1,2)$. There is also some evidence in animals and in man that hypokalemia when present in the hyponatremic state could predispose to the development of demyelination during correction of the hyponatremia $(3,4)$. Taking into consideration the close link between magnesium, phosphorus and potassium concentrations, the emergence of the concurrent electrolyte disorders in hyponatremic patients may be of paramount importance $(5-8)$. We undertook the present study to determine the incidence of electrolyte abnormalities encountered in hyponatre- mic patients admitted to our clinic, as well as to illuminate possible pathophysiologic mechanisms responsible for the development of these disorders.

\section{Patients and Methods}

During a period of 2.5 years (starting from 5 February 1999), we prospectively studied non selected consecutive adult patients (over years 18 of age), who either on admission to our internal medicine clinic or during their hospitalization were found to have hyponatremia. To be eligible, patients had to have a serum sodium concentration $\left(\left[\mathrm{Na}^{+}\right]\right)$of less than $130 \mathrm{meq} / \mathrm{L}$ (reference range 134-145 meq/L) in 2 sequential measurements to exclude potential laboratory errors. Hyperglycemic patients with serum glucose concentrations $>180 \mathrm{mg} / \mathrm{dL}$ were excluded from the study. On admis- 
Table 1. Causes of Hyponatremia

\begin{tabular}{|l|c|c|}
\hline Cause & N & Percentage, \% \\
\hline SIADH* & 55 & 26.9 \\
\hline Extracellular volume depletion & 53 & 26.0 \\
\hline Diuretics & 40 & 19.6 \\
\hline Edematous states** & 39 & 19.1 \\
\hline Various causes*** & 17 & 8.3 \\
\hline
\end{tabular}

*SIADH: syndrome of inappropriate ADH

**Edematous states include hepatic cirrhosis $(\mathrm{n}=20)$, heart failure $(\mathrm{n}=16)$,

nephrotic syndrome with marked hypoalbuminemia $(n=3)$

**Various causes include primary polydipsia $(n=6)$, cerebral salt wasting $(n=3)$,

adrenal insufficiency $(n=3)$, salt-wasting nephropathy $(n=3)$, and hypothyroidism $(n=2)$.

sion, a detailed history was obtained with emphasis on dietary intake, and drug administration. Moreover, each patient underwent a complete physical examination with special attention to orthostatic changes in pulse rate and blood pressure, jugular venous pressure, skin turgor, moisture in the axillae, and hydration of mucous membranes. Orthostatic hypotension and orthostatic change in pulse rate were defined as the reduction in systolic blood pressure of at least $20 \mathrm{~mm} \mathrm{Hg}$ and the increase in pulse rate of at least $10 \%$ after $2 \mathrm{~min}$ in the upright position compared to the supine position, respectively.

Furthermore, the detection of the cause of hyponatremia was one of our primary tasks. Diagnostic approach was based on history, physical examination and laboratory tests (2). Particularly, hyponatremia due to extracellular volume depletion was diagnosed in patients with historical (e.g. vomiting, diarrhea), clinical (such as postural changes in blood pressure and pulse rate, decreased skin turgor or axillary moisture, and dry mucous membranes), or/and laboratory [serum urea to creatinine ratio greater than 40 , urine sodium less than $20 \mathrm{meq} / \mathrm{L}$ and fractional excretion of sodium $\left(\mathrm{FENa}^{+}\right)<1 \%$ ] indications of hypovolemia. The diagnosis of the syndrome of inappropriate antidiuretic hormone (SIADH) was made in patients who fulfilled the following criteria: 1) hyponatremia and hypoosmolalality; 2) increased urine osmolality (Uosm > $100 \mathrm{mOsm} / \mathrm{kg}$ ); 3) inappropriate natriuresis (> $40 \mathrm{meq} / \mathrm{L}$ ); 4) normovolemia; 5) normal renal, adrenal, and thyroid function; and 6) normal acid-base and potassium balance (9). The diagnosis of SIADH was also supported by the presence of hypouricemia, as well as by the low serum urea and phosphate levels, if present.

In patients with heart failure, hepatic cirrhosis or nephrotic syndrome edematous hyponatremia was defined as the presence of more than $0.5 \mathrm{~cm}$ of pressure-induced dependent edema or ascites and absence of historical and clinical evidence of extracellular volume depletion.

Diuretic-induced hyponatremia was defined as hyponatremia in patients receiving diuretics but in the absence of heart failure, hepatic cirrhosis, nephrotic syndrome, extracellular volume depletion unrelated to diuretics, renal insufficiency unrelated to diuretics, and SIADH.

Prior to any therapeutic intervention, venous blood was obtained for the determination of serum glucose, urea, creatinine, uric acid, sodium, potassium, chloride, calcium, magnesium, phosphorus, total proteins, albumin, triglycerides, osmolality $\left(\mathrm{P}_{\mathrm{osm}}\right)$, cortisol and thyroid-stimulating hormone (TSH). Arterial blood was also obtained for blood gas measurements. At the same time, a fresh urine specimen was tested for osmolality ( $\left.\mathrm{U}_{\text {osm}}\right)$, glucose, urea, creatinine, uric acid, sodium, potassium, chloride, calcium, magnesium, phosphorus and proteins. A standard formula was used for the determination of the fractional excretion (FE) of electrolytes. It should be mentioned that $\mathrm{FEK}^{+}>9 \%, \mathrm{FEPO}_{4}{ }^{3-}>$ $20 \%, \mathrm{FEMg}^{2+}>4 \%$ and $\mathrm{FECa}^{+2}>3 \%$ denote high renal excretion of these parameters (10-14).

Laboratory determinations were done by automated chemical analysis in our laboratory using an Olympus AU 600 analyzer (Olympus Diagnostica, Hamburg, Germany). Specifically, urine and serum samples were analyzed using ion-sensitive electrodes for sodium, potassium, chloride, and calcium, and photometric assays for phosphorus and magnesium. The glutamate dehydrogenase method was used for the determination of urea levels, and a modification of the Jaffe method for creatinine measurement. Serum total protein concentrations were measured by the Biuret method, and serum albumin by the bromocresol green method. The hexokinase and uricase methods were used for the determination of glucose and uric acid levels, respectively. Serum triglycerides were determined by enzymatic colorimetric assay. TSH was measured by microparticle enzyme immunoassay (ABBOTT GmbH Diagnostika, WiesbadenDelkenheim, Germany), while serum cortisol levels were estimated by competitive immunoassay (competitive ELISA, Immulite, DPC, Los Angeles, CA, USA).

Arterial $\mathrm{pH}$ and $\mathrm{PCO}_{2}$ were determined using a $\mathrm{pH}$ blood gas analyzer, and serum bicarbonate was calculated from blood carbon dioxide tension according to the HendersonHasselbalch equation with an acidity exponent of 6.10 and a solubility coefficient of 0.0301 .

\section{Statistical analysis}

The results are expressed as mean \pm SD. Chi-square test was used for comparisons between groups. $\mathrm{P}$ values less than 0.05 were considered to indicate statistical significance.

\section{Results}

Two hundred and four patients (104 males, 100 females) fulfilled the criteria for inclusion in the study. The causes of hyponatremia are listed in Table 1 . Ninety-two patients $(45.5 \%)$ had at least one electrolyte abnormality. The electrolyte disorders in the study population are shown in Table 2 .

Of the 40 patients with diuretic-induced hyponatremia, 12 
Table 2. Electrolyte Abnormalities in Patients with Hyponatremia

\begin{tabular}{|c|c|c|c|c|c|c|}
\hline Abnormality & $\begin{array}{c}\text { All } \\
\text { patients }\end{array}$ & SIADH & $\begin{array}{l}\text { Hypo- } \\
\text { volemia }\end{array}$ & Diuretics & $\begin{array}{l}\text { Edematous } \\
\text { states }\end{array}$ & $\begin{array}{l}\text { Various } \\
\text { causes }\end{array}$ \\
\hline $\begin{array}{l}\text { Hypokalemia } \\
\text { (serum potassium } \\
<3.5 \mathrm{meq} / \mathrm{L} \text { ) }\end{array}$ & $\begin{array}{l}32 / 204 \\
(15.8 \%)\end{array}$ & $\begin{array}{c}3 / 55 \\
(5.4 \%)^{\S, \dagger}\end{array}$ & $\begin{array}{c}7 / 53 \\
(13.2 \%)^{\S, \dagger}\end{array}$ & $\begin{array}{l}12 / 40 \\
(30 \%)\end{array}$ & $\begin{array}{c}4 / 39 \\
(10.2 \%)^{\S, \dagger}\end{array}$ & $\begin{array}{c}6 / 17 \\
(35.2 \%)\end{array}$ \\
\hline $\begin{array}{l}\text { Hyperkalemia } \\
\text { (serum potassium } \\
>5.5 \mathrm{meq} / \mathrm{L} \text { ) }\end{array}$ & $\begin{array}{l}12 / 204 \\
(5.9 \%)\end{array}$ & $\begin{array}{l}0 / 55 \\
(0 \%)\end{array}$ & $\begin{array}{c}3 / 53 \\
(5.6 \%)^{9}\end{array}$ & $\begin{array}{l}0 / 40 \\
(0 \%)\end{array}$ & $8 / 39(20.5 \%)$ & $\begin{array}{c}1 / 17 \\
(5.9 \%)\end{array}$ \\
\hline $\begin{array}{l}\text { Hypomagnesemia } \\
\text { (serum magnesium } \\
<1.3 \mathrm{meq} / \mathrm{L} \text { ) }\end{array}$ & $\begin{array}{l}31 / 204 \\
(15.2 \%)\end{array}$ & $\begin{array}{c}3 / 55 \\
(5.4 \%)^{\S, \dagger}\end{array}$ & $\begin{array}{c}7 / 53 \\
(13.2 \%)^{\S}\end{array}$ & $\begin{array}{c}12 / 40 \\
(30.0 \%)\end{array}$ & $\begin{array}{c}4 / 39 \\
(10.2 \%)^{\S}\end{array}$ & $\begin{array}{c}5 / 17 \\
(29.4 \%)\end{array}$ \\
\hline $\begin{array}{l}\text { Hypermagnesemia } \\
\text { (serum magnesium } \\
>2.1 \mathrm{meq} / \mathrm{L} \text { ) }\end{array}$ & $\begin{array}{l}4 / 204 \\
(1.9 \%)\end{array}$ & $\begin{array}{l}0 / 55^{\dagger} \\
(0 \%)^{\dagger}\end{array}$ & $\begin{array}{c}2 / 53 \\
(3.7 \%)\end{array}$ & $\begin{array}{l}0 / 40 \\
(0 \%)\end{array}$ & $\begin{array}{l}0 / 39 \\
(0 \%)\end{array}$ & $\begin{array}{c}2 / 17 \\
(11.7 \%)^{\S, \text { }}\end{array}$ \\
\hline $\begin{array}{l}\text { Hypophosphatemia } \\
\text { (serum phosphorus } \\
<2.5 \mathrm{mg} / \mathrm{dL} \text { ) }\end{array}$ & $\begin{array}{l}35 / 204 \\
(17.0 \%)\end{array}$ & $\begin{array}{c}15 / 55 \\
(27.2 \%)\end{array}$ & $\begin{array}{c}8 / 53 \\
(15.0 \%)\end{array}$ & $\begin{array}{c}5 / 40 \\
(12.5 \%)\end{array}$ & $6 / 39(15.4 \%)$ & $\begin{array}{c}1 / 17 \\
(5.9 \%)\end{array}$ \\
\hline $\begin{array}{l}\text { Hyperphospha- } \\
\text { temia (serum } \\
\text { phosphorus > } 5 \\
\mathrm{mg} / \mathrm{dL} \text { ) }\end{array}$ & $\begin{array}{l}5 / 204 \\
(2.5 \%)\end{array}$ & $\begin{array}{l}0 / 55 \\
(0 \%)\end{array}$ & $\begin{array}{c}3 / 53 \\
(5.6 \%)\end{array}$ & $\begin{array}{l}0 / 40 \\
(0 \%)\end{array}$ & $\begin{array}{c}1 / 39 \\
(2.5 \%)\end{array}$ & $\begin{array}{c}1 / 17 \\
(5.9 \%)\end{array}$ \\
\hline $\begin{array}{l}\text { Hypocalcemia } \\
\text { (serum calcium < } \\
8.2 \mathrm{mg} / \mathrm{dL} \text { ) }\end{array}$ & $\begin{array}{l}49 / 204 \\
(24 \%)\end{array}$ & $\begin{array}{c}10 / 55 \\
(18.2 \%)^{\uparrow, \S}\end{array}$ & $\begin{array}{c}10 / 53 \\
(18.8 \%)^{\uparrow, \S}\end{array}$ & $\begin{array}{c}1 / 40 \\
(2.5 \%)^{\top}\end{array}$ & $\begin{array}{c}26 / 39 \\
(66.6 \%)\end{array}$ & $\begin{array}{c}2 / 17 \\
(11.7 \%)^{\pi}\end{array}$ \\
\hline True & $6 / 204$ & $3 / 55$ & $1 / 53$ & $0 / 40$ & $1 / 39$ & $1 / 17$ \\
\hline hypocalcemia* & $(2.9 \%)$ & $(5.4 \%)$ & $(1.8 \%)$ & $(0 \%)$ & $(2.5 \%)$ & $(5.9 \%)$ \\
\hline $\begin{array}{l}\text { Hypercalcemia } \\
\text { (serum calcium > } \\
10.8 \mathrm{mg} / \mathrm{dL} \text { ) }\end{array}$ & $\begin{array}{l}3 / 204 \\
(1.4 \%)\end{array}$ & $\begin{array}{c}1 / 55 \\
(1.8 \%)\end{array}$ & $\begin{array}{l}0 / 53 \\
(0 \%)\end{array}$ & $\begin{array}{l}2 / 40 \\
(5 \%)\end{array}$ & $\begin{array}{l}0 / 39 \\
(0 \%)\end{array}$ & $\begin{array}{l}0 / 17 \\
(0 \%)\end{array}$ \\
\hline Total & $\begin{array}{l}92 / 204 \\
(45.5 \%)\end{array}$ & $\begin{array}{c}21 / 55 \\
(38.8 \%)\end{array}$ & $\begin{array}{c}21 / 53 \\
(39.6 \%)\end{array}$ & $\begin{array}{c}22 / 40 \\
(55.0 \%)\end{array}$ & $\begin{array}{c}22 / 39 \\
(56.4 \%)\end{array}$ & $\begin{array}{c}9 / 17 \\
(52.9 \%)\end{array}$ \\
\hline \multicolumn{7}{|c|}{ *True hypocalcemia denotes hypocalcemia after adjustment for serum albumin concentration } \\
\hline
\end{tabular}

(30\%) were receiving hydrochlorothiazide (12.5-25 mg/day), $11(27.5 \%)$ the fixed combination of hydrochlorothiazide (50 mg/day) plus amiloride (5 mg/day), 6 (15\%) indapamide $(2.5 \mathrm{mg} /$ day $)$, and 5 (12.5\%) chlorthalidone (25-50 $\mathrm{mg} /$ day). The remaining 6 patients $(15 \%)$ developed hyponatremia while taking various combinations of diuretic agents (hydrochlorothiazide or chlorthalidone plus furosemide or spironolactone). In all patients hypertension was the indication for diuretic administration. It should be noted that in all patients the serum sodium concentration gradually increased after stopping the diuretics. Twenty-two patients (55\%) with diuretic-induced hyponatremia had at least one additional electrolyte disturbance. As shown in Table 2, 12 patients (30\%) had hypokalemia (range 2.2-3.4 meq/L), which was due to inappropriate kaliuresis $\left(\mathrm{FEK}^{+}>9 \%\right)$ in all but one patient. Five of the hypokalemic patients also had hypomagnesemia. All together, 12 patients with diuretic-induced hyponatremia $(30 \%)$ exhibited hypomagnesemia (range 0.6$1.23 \mathrm{meq} / \mathrm{L}$ ), which was accompanied by inappropriate magnesiuria $\left(\mathrm{FEMg}^{2+}>4 \%\right)$ in all but one patient. Hypophos- 
phatemia (range 1.7-2.4 meq/L) was found in 5 patients $(12.5 \%)$ and was attended by inappropriate phosphaturia $\left(\mathrm{FEPO}_{4}{ }^{3-}>20 \%\right)$ in all these subjects. Four of the hypophosphatemic patients also had hypokalemia, whereas in 2 of these patients hypomagnesemia was also present.

Of patients with SIADH, $21(38.8 \%)$ had at least one additional electrolyte abnormality. Hypophosphatemia (range 1.6-2.4 meq/L) was the most frequent electrolyte disorder observed in 15 patients $(27.2 \%)$ and was accompanied by inappropriate phosphaturia in all these patients. Interestingly, 3 hypophosphatemic patients presented also with hypokalemia caused by inappropriate kaliuresis, hypomagnesemia with renal magnesium wasting, and hypocalcemia with inappropriate calciuria.

Twenty-one hyponatremic patients $(39.6 \%)$ due to extracellular volume depletion had one or more additional electrolyte abnormalities. Hypokalemia (range 2.7-3.4 meq/L) was observed in 7 patients (13.2\%). Five of the hypokalemic patients had hypomagnesemia and inappropriate kaliuresis, while the remaining 2 patients had a history of gastrointestinal fluid losses. Additionally, all but one hypokalemic patients experienced alkalemia. Hypomagnesemia (range 0.9$1.2 \mathrm{meq} / \mathrm{L})$ was seen in 7 patients $(13.2 \%)$ with hypovolemic hyponatremia. Five of the hypomagnesemic patients had both inappropriate magnesiuria and at least one additional acid-base or electrolyte disorder: hypokalemia $(n=3)$, hypophosphatemia $(n=3)$, alkalemia $(n=3)$, and lactic acidosis $(n=2)$. The remaining 2 hypomagnesemic patients presented with diarrhea. Eight patients (15\%) with hypovolemic hyponatremia had hypophoshatemia (range 2.1-2.4 meq/L). Five of the hypophosphatemic patients had inappropriate phosphaturia. Of these, 3 patients also exhibited both hypomagnesemia and alkalemia, while lactic acidosis was evident in the other 2 patients. The remaining 3 hypophosphatemic patients had an acute diarrhea syndrome. Additionally, hyperkalemia $(n=3)$, hyperphosphatemia $(n=3)$ and hypermagnesemia $(n=2)$ was observed in patients with hyponatremia due to extracellular volume depletion and coexistent prerenal acute renal failure (the mean serum creatinine concentration was $2.8 \pm 0.8 \mathrm{mg} / \mathrm{dL})$. Finally, 31 patients $(58 \%)$ with hypovolemic hyponatremia exhibited alkalemia (arterial $\mathrm{pH}>7.45)$. Of those, 7 patients $(13.2 \%)$ had respiratory alkalosis, 4 (7.5\%) had metabolic alkalosis, while 20 patients $(37.7 \%)$ had metabolic alkalosis coexisting with a primary respiratory alkalosis.

Twenty-two hyponatremic patients $(56.4 \%)$ due to edematous states had at least one additional electrolyte abnormality. It should be noted that all patients with heart failure were receiving an angiotensin-converting enzyme inhibitor plus furosemide (40-80 mg/day), while all patients with hepatic cirrhosis were receiving spironolactone (100-400 mg/ day) \pm furosemide (40-160 mg/day). As shown in Table 2, hyperkalemia (range 5.8-6.9 meq/L) was found in 8 patients $(20.5 \%)$ with edematous hyponatremia. Moreover, 6 patients (15.4\%) exhibited hypophosphatemia (range 1.8-2.4 meq/L) that was accompanied by inappropriate phosphaturia. Three hypophosphatemic patients had also hypomagnesemia, while alkalemia (respiratory alkalosis, either alone or in combination with metabolic alkalosis) was observed in all but one patient. Hypokalemia (range 2.5-3.4 meq/L) was observed in 4 patients $(10.2 \%)$ and was associated by inappropriate kaliuresis in all of these. Two hypokalemic patients had also hypomagnesemia. In 4 patients $(10.2 \%)$ with edematous hyponatremia, low serum magnesium levels were found that were accompanied by inappropriate magnesiuria in all but one patient. All patients with hypokalemia and hypomagnesemia also had alkalemia. Furthermore, hyperphosphatemia was seen in one patient with acute renal failure.

There were no statistically significant differences regarding the incidence of the additional electrolyte abnormalities (as a whole) among the subgroups of hyponatremic patients. However, hypokalemia and hypomagnesemia were more frequently observed in patients with diuretic-induced hyponatremia, while hyperkalemia in edematous hyponatremia (as compared with all the other subgroups). Additionally, as far as the incidence of hypophosphatemia is concerned there were no statistically significant differences between the subgroups of hyponatremic patients (Table 2). It should be noted that in all subgroups of patients, the serum sodium concentration was not correlated with the serum levels of all the other electrolytes studied (data not shown).

\section{Discussion}

Additional electrolyte abnormalities were observed in a considerable percentage of our hyponatremic patients independent of the cause of hyponatremia. Taking into consideration the absence of statistically significant correlations between serum sodium and other electrolyte levels, these disturbances should be ascribed mainly to the underlying cause of hyponatremia rather than to hyponatremia per se.

More than half of patients with diuretic-induced hyponatremia exhibited at least one additional electrolyte abnormality. Specifically, hypokalemia, hypomagnesemia, and hypophosphatemia were detected in a substantial fraction of these patients. Potassium, magnesium and phosphorus depletion can be induced by diuretic therapy as a result of urinary losses (15-17). Furthermore, experimental and clinical observations have demonstrated a close link among potassium, magnesium, and phosphorus concentrations (5-8). Indeed, potassium depletion is associated with increased urinary excretion of magnesium, calcium, and phosphorus, while magnesium depletion causes kaliuresis and potassium depletion $(6,7,18)$. Moreover, magnesium depletion leads to renal phosphate wasting and phosphate depletion, although hypophosphatemia only rarely develops (19).

Hypophosphatemia was the most frequent electrolyte disorder in patients with hyponatremia due to SIADH. However, this parameter lacks satisfactory specificity in diagnosing SIADH given that hypophosphatemia was not infrequently observed in the other subgroups of our hyponatremic patients. Hypophosphatemia in SIADH patients can be 
attributed to volume expansion, since experimental studies clearly showed that volume expansion evoked an inhibition of phosphate uptake by the renal proximal tubules (20). In fact, in our study all hypophosphatemic patients due to SIADH exhibited inappropriate phosphaturia. Apart from hypophosphatemia, other electrolyte disorders have infrequently been described in patients with SIADH. Interestingly, 3 of our SIADH subjects presented with a constellation of metabolic abnormalities and specifically hypophosphatemia, hypokalemia with inappropriate kaliuresis, hypomagnesemia caused by renal magnesium wasting, as well as hypocalcemia with inappropriate calciuria. Volume expansion and coexistent hypophosphatemia that both decrease passive magnesium reabsorption might explain the hypomagnesemia observed. Moreover, the potassium wasting observed should be ascribed to the coexistent hypomagnesemia or less possibly to the hypotonicity-induced elevation of aldosterone secretion, which is observed when plasma osmolality falls below $240 \mathrm{mosm} / \mathrm{kg}$ and can counterbalance the influence of the extracellular fluid expansion on reninaldosterone axis $(21,22)$. Moreover, hypocalcemia should be attributed to the coexistent hypomagnesemia, which is known to impair the release of parathyroid hormone (PTH) and induce skeletal resistance to its actions $(23,24)$. Hypophosphatemia-related calciuria could also have contributed to the observed hypocalcemia taking into consideration that low serum phosphorus levels stimulate the production of 1,25-dihydroxy-vitamin D, which leads to an augmented intestinal calcium absorption and hypercalciuria $(25,26)$. Consequently, in few SIADH patients multiple interrelated electrolyte abnormalities may be found, which could, at least partially, be ascribed to the extracellular volume expansion.

In hypovolemic hyponatremia, $15 \%$ of patients exhibited hypokalemia that may be attributed to hypomagnesemia related kaliuria or to gastrointestinal potassium loss, while the coexistent alkalemia may also have played a contributory role. Moreover, renal and extrarenal magnesium loss were the main pathogenetic mechanisms regarding the emergence of hypomagnesemia in these patients, whereas an increased transcellular magnesium shift from the extracellular to intracellular department may have contributed to the decreased serum magnesium levels in patients with alkalemia.
Finally, metabolic acidosis and phosphate depletion observed in some hypomagnesemic patients could have been responsible for the inappropriate magnesiuria, which has been shown to arise from reduced magnesium reabsorption in the loop of Henle as well as in the distal tubule $(27,28)$. Inappropriate urinary phosphate loss was the leading cause of hypophoshatemia observed in our hyponatremic patients due to extracellular volume depletion. This inappropriate phosphaturia was attributed to hypomagnesemia, or acidemia. Even though hypophosphatemia could be the cause of inappropriate magnesiuria and hypomagnesemia, in some cases, it might also be the result of hypomagnesemia $(29,30)$. Acute metabolic acidosis also causes loss of phosphate in the urine and enhances cellular release of the phosphate anions (31). Additionally, intracellular shift of phosphate may have played a prominent role in the development of hypophoshatemia in patients with alkalosis.

Hyperkalemia was observed in a considerable percentage of patients with edematous hyponatremia and can be mainly ascribed to the administration of converting enzyme inhibitors or potassium-sparing diuretics (mainly spironolactone) in the setting of effective circulating volume depletion. Furthermore, low potassium or magnesium dietary intake in malnourished patients with severe heart or hepatic failure as well as the alkalemia-related transcellular shift of these ions from the extracellular to the intracellular department significantly contributes to the decreased serum potassium or magnesium levels occasionally encountered in these patients. However, the leading cause of both hypokalemia and hypomagnesemia in patients with edematous hyponatremia was the administration of furosemide (32). Moreover, hypophosphatemia was mainly due to inappropriate phosphaturia, which can be attributed to hypomagnesemia as well as to a phosphaturic effect of diuretics. Intracellular shift of phosphate in patients with alkalosis (33), as well as a decreased intake of phosphorus-rich food may also have played a contributory role in the development of hypophosphatemia.

In conclusion, additional electrolyte abnormalities are frequently seen in hyponatremic patients, independently of hyponatremia cause, due to various interrelated pathogenetic mechanisms. The most common of these disorders include hypophosphatemia, hypokalemia and hypomagnesemia.

\section{References}

1. Graber M, Corish D. The electrolytes in hyponatremia. Am J Kidney Dis 18: 527-545, 1991.

2. Milionis HJ, Liamis GL, Elisaf MS. The hyponatremic patient: a systematic approach to laboratory diagnosis. CMAJ 166: 10561062, 2002.

3. Lien YH, Martin DK. Potassium depletion is a predisposing factor for osmotic demyelination syndrome: a survival, histopathology and biochemistry study. J Am Soc Nephrol 2: 764, 1991.

4. Lohr JW. Osmotic demyelination syndrome following correction of hyponatremia: association with hypokalemia. Am J Med 96: 408-413, 1994.
5. Lemann J, Pleuss JA, Gray RW, Hoffmann RG. Potassium administration increases and potassium deprivation reduces urinary calcium excretion in healthy adults. Kidney Int 39: 973-983, 1991.

6. Elisaf M, Merkouropoulos M, Tsianos EV, Siamopoulos KC. Pathogenetic mechanisms of hypomagnesemia in alcoholic patients. J Trace Elements Med Biol 9: 210-214, 1995.

7. Solomon R. The relationship between disorders of $\mathrm{K}^{+}$and $\mathrm{Mg}^{+}$homeostasis. Semin Nephrol 2: 253-262, 1987.

8. Anderson J, Foster JB. Effect of cortisone on phosphate excretion in man. Clin Sci 18: 437-439, 1959.

9. Bartter FC, Schwartz WB. The syndrome of inappropriate secre- 
tion of antidiuretic hormone. Am J Med 42: 790-806, 1967.

10. Jones JW, Sebastian A, Hulter HN, Schmbelan M, Sutton JM, Biglieri EG. Systemic and renal acid-base effects of chronic dietary potassium depletion in humans. Kidney Int 21: 402-410, 1982.

11. West ML, Marsden PA, Richardson RM, Zettle RM, Halperin ML. New clinical approach to evaluate disorders of potassium excretion. Miner Electrolyte Metab 12: 234-238, 1986.

12. Elisaf M, Siamopoulos KC. Fractional excretion of potassium in normal subjects and in hypokalemic patients. Postgrad Med J 71: 211-212, 1995.

13. Elisaf M, Panteli K, Theodorou J, Siamopoulos KC. Fractional excretion of magnesium in normal subjects and in patients with hypomagnesemia. Magn Res 10: 315-320, 1997.

14. Narins RG, Jones RG, Stom MC, Rudnick MR, Gastl CP. Diagnostic strategies in disorders of fluid, electrolyte and acid-base homeostasis. Am J Med 72: 496-520, 1982.

15. Swales JD. Magnesium deficiency and diuretics. Br Med J 285 : 1377-1384, 1982.

16. Itescu SH, Haskell LP, Tannenberg AM. Thiazide-induced clinically significant hypophosphatemia. Clin Nephrol 27: 161-162, 1987.

17. Plante GE, Lafreniere MC, Tam PT, Sirois P. Effect of indapamide on phosphate metabolism and vascular reactivity. Am J Med 84 (Suppl 1B): 26-30, 1988

18. Wu X, Ackermann U, Sonnenberg H. Potassium depletion and salt-sensitive hypertension in DAHL rats: effect on calcium, magnesium, and phosphate excretions. Clin Exp Hypertens 17: 9891008, 1995.

18. Knochel JP. The pathophysiology and clinical characteristics of severe hypophosphatemia. Arch Intern Med 137: 203-220, 1977.

20. Wesson LG. Hoemostasis of phosphate revisited. Nephron 77 : 249-266, 1997

21. Rizos E, Liamis G, Elisaf M. Multiple metabolic abnormalities in a patient with the syndrome of inappropriate antidiuresis. Nephron 91: 339-340, 2002
22. Taylor RE Jr, Glass JT, Radke KJ, Schneider EG. Specificity of effect of osmolality on aldosterone secretion. Am J Physiol 252: E 118-E125, 1987.

23. Anast CS, Winnacker JL, Forte LR, Burns TW. Impaired release of parathyroid hormone in magnesium deficiency. J Clin Endocrinol Metab 42: 707-717, 1976.

24. Freitag JJ, Martin KJ, Conrades MB, et al. Evidence for skeletal resistance to parathyroid hormone in magnesium deficiency. Studies in isolated perfused bone. J Clin Invest 64: 1238-1244, 1979.

25. Coyle S, Masters PW, Barnard D. TmP/GFR and ionized calcium in the management of severe hypophosphataemia. Ann Clin Biochem 29(Pt 5): 567-569, 1992.

26. Navarro JF, Teruel JL, Montalban C, Gallego N, Ortuno J. Hypercalciuria secondary to chronic hypophosphatemia. Miner Electrolyte Metab 20: 255-258, 1994.

27. Lennon EJ, Piering WF. A comparison of the effects of glucose ingestion and $\mathrm{NH}_{4} \mathrm{Cl}$ acidosis on urinary calcium and magnesium excretion in man. J Clin Invest 49: 1458-1465, 1970.

28. Dominguez JH, Gray RW, Lemann J Jr. Dietary phosphate deprivation in women and men: effects on mineral and acid balances, parathyroid hormone and the metabolism of 25-OH-vitamin D. J Clin Endocrinol Metab 43: 1056-1068, 1976.

29. Whang R, Welt LG. Observations in experimental magnesium depletion. J Clin Invest 42: 305-313, 1963.

30. Ginn HE, Shanbour LL. Phosphaturia in magnesium-deficient rats. Am J Physiol 212: 1347-1350, 1967.

31. Kempson SA. Effect of metabolic acidosis on renal brushborder membrane adaptation to low phosphorus diet. Kidney Int 22: 225-233, 1982.

32. Milionis H, Alexandrides G, Liberopoulos E, Bairaktari E, Goudevenos J, Elisaf M. Hypomagnesemia and concurrent acid-base and electrolyte abnormalities in patients with congestive heart failure. Eur J Hear Failure 4: 167-173, 2002.

33. Brautbar N, Leibovici H, Massry SG. On the mechanism of hypophosphatemia during acute hyperventilation: evidence for increased muscle glycolysis. Miner Electrolyte Metab 9: 45-50, 1983.

(C) 2007 The Japanese Society of Internal Medicine http://www.naika.or.jp/imindex.html 